Effects of the number of periods on strai $n$ in super I at t i ces

\begin{tabular}{|l|l|}
\hline 著者 & $\begin{array}{l}\text { N shi da K, Hagi war a S., Ter ani shi M, } \\
\text { Si rakawa O. H r akai A., Kat oda T. }\end{array}$ \\
\hline $\begin{array}{l}\text { j our nal or } \\
\text { publ i cat i on t i t l e }\end{array}$ & Journal of Appl i ed Physi cs \\
\hline vol une & 91 \\
\hline nunber & 8 \\
\hline page r ange & $5155-5157$ \\
\hline year & $2002-04$ 15 \\
\hline URL & ht t p: //hdl . handl e. net $/ 10173 / 799$ \\
\hline
\end{tabular}




\section{AIP Aapolied Physics}

\section{Effects of the number of periods on strain in superlattices}

K. Nishida, S. Hagiwara, M. Teranishi, O. Sirakawa, A. Hirakai et al.

Citation: J. Appl. Phys. 91, 5155 (2002); doi: 10.1063/1.1462419

View online: http://dx.doi.org/10.1063/1.1462419

View Table of Contents: http://jap.aip.org/resource/1/JAPIAU/v91/i8

Published by the American Institute of Physics.

\section{Related Articles}

Structural properties and spatial ordering in multilayered ZnMgTe/ZnSe type-II quantum dot structures J. Appl. Phys. 111, 033516 (2012)

Piezoelectric superlattices as multi-field internally resonating metamaterials AIP Advances 1, 041504 (2011)

Effect of built-in electric field on the temperature dependence of transition energy for InP/GaAs type-II superlattices

J. Appl. Phys. 110, 123523 (2011)

Polarization property of deep-ultraviolet light emission from C-plane AIN/GaN short-period superlattices Appl. Phys. Lett. 99, 251112 (2011)

Tunable superlattice in-plane thermal conductivity based on asperity sharpness at interfaces: Beyond Ziman's model of specularity

J. Appl. Phys. 110, 113529 (2011)

\section{Additional information on J. Appl. Phys.}

Journal Homepage: http://jap.aip.org/

Journal Information: http://jap.aip.org/about/about_the_journal

Top downloads: http://jap.aip.org/features/most_downloaded

Information for Authors: http://jap.aip.org/authors

\section{ADVERTISEMENT}
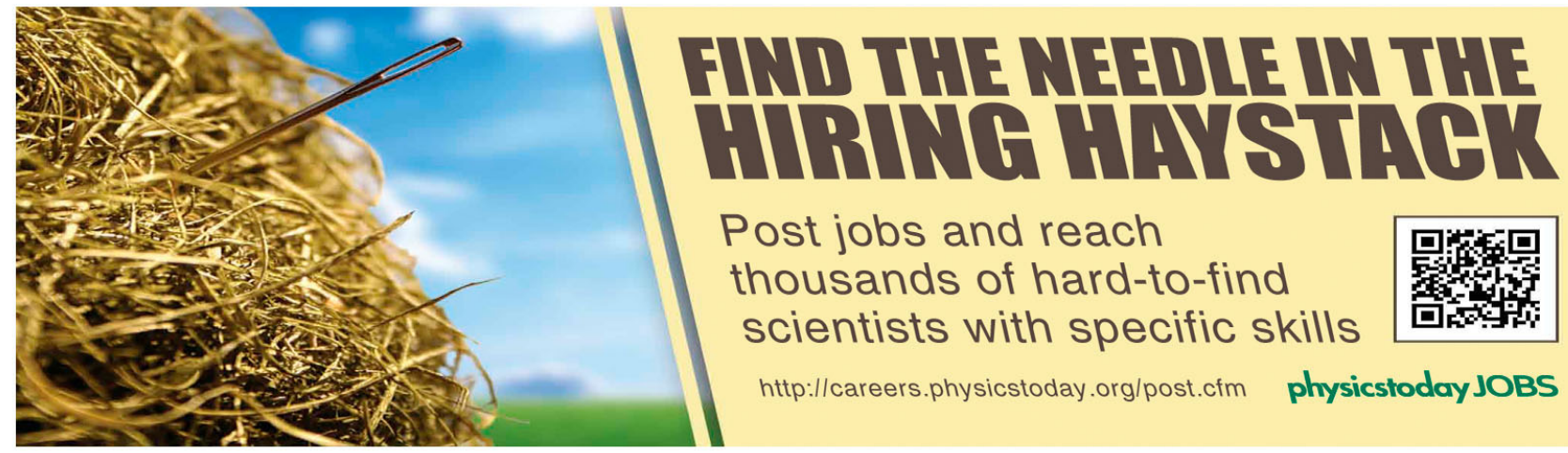


\title{
Effects of the number of periods on strain in superlattices
}

\author{
K. Nishida, ${ }^{\text {a) }}$ S. Hagiwara, ${ }^{\text {b) }}$ M. Teranishi, O. Sirakawa, A. Hirakai, and T. Katoda \\ Department of Electronic and Photonic Systems Engineering, Faculty of Engineering, Kochi University \\ of Technology, 185 Miyanokuchi, Tosayamada-cho, Kamigun, Kochi 782-8502, Japan
}

(Received 9 February 2001; accepted for publication 25 January 2002)

\begin{abstract}
The effect of periods on the accumulation and release of stress in GaAs/AlInAs superlattices structure is reported here. It is observed that in GaAs/AlInAs superlattices, when the Indium (In) content is greater than $10 \%$, stress accumulates monotonically as the number of period increases. In GaAs/AlInAs superlattices with an In content of 5\%, the accumulated stress is larger when the number of periods is less than 10 . However when the number of periods exceeds 10, it was observed that suddenly there is a significant increase in defects and stress release. However, with any further increase in period number, there is once again an accumulation of stress. (C) 2002 American Institute of Physics. [DOI: 10.1063/1.1462419]
\end{abstract}

\section{INTRODUCTION}

Superlattices $(\mathrm{SLs})^{1-4}$ and strained superlattice structures $^{5-7}$ are already in use in many devices and are expected to be used increasingly in the future. In general, defects are formed in a strained SL when the strain exceeds a threshold. ${ }^{8,9}$ No relation has been proposed for the number of periods. Moreover, it is difficult to characterize the strain inside the SL structure. Laser Raman spectroscopy could be useful tool for characterizing the strain in the SL structure because laser light can penetrate the sample due the absence of absorption at this wavelength.

In this article, we propose a possible relation between the number of periods in a GaAs/AlInAs SL and the accumulated strain in the GaAs layers of this superlattices structure as measured with laser Raman spectroscopy.

\section{EXPERIMENT}

A series of $(\mathrm{GaAs})_{n}(\mathrm{AlInAs})_{n}$ SLs were grown on (100) semi-insulating GaAs substrates by molecular beam epitaxy. High purity In, Ga, Al, As, and Si were used as sources. The growth temperature of a GaAs buffer layer and the superlattices structure was $540^{\circ} \mathrm{C}$. Figure 1 is a schematic drawing of the sample.

Growths were carried out by varying the number of periods and the In content of the InAlAs layer for changing the accumulation of the strain in the SL.

First, a set of four semiconductor layers, GaAs $20 \mathrm{~nm}$, InAlAs $15 \mathrm{~nm}$, Si-doped InAlAs (Si-InAlAs) $25 \mathrm{~nm}$, and InAlAs $15 \mathrm{~nm}$, were grown with periods varying between 5 and 30 as multiquantum well layers. The GaAs layers act as wells and the other layers act as barriers. The $\mathrm{Si}-\mathrm{InAlAs}$ layers were introduced in order to increase the number of electrons in the conduction band of the GaAs well because one of the purposes of forming the SLs was to characterize

\footnotetext{
a) Author to whom correspondence should be addressed; electronic mail: nishida.ken@kochi-tech.ac.jp

b) Also with: Department of Electronic Engineering, The Faculty of Engineering, The University of Tokyo 7-3-1 Hongo Bunkyo-ku, Tokyo 1138656, Japan.
}

the subbands in the well. The electronic properties of these superlattices will be reported elsewhere. The In content in the InAlAs was changed from $5 \%$ to $15 \%$ to vary the lattice constant.

The Raman spectrum was measured to determine the strain in the SL. The measurement system used was JRS400T (JEOL Ltd.) with an $\mathrm{Ar}^{+}$laser (514.5 nm) as an excitation source. The strain in the GaAs layers in the SL was characterized based on the shift in the GaAs longitudinal optical (LO)-phonon frequency in the Raman spectrum. The reason why InAlAs was used rather than InGaAs is as follows. In general, when the frequency of the laser light is coincident with an eigenfrequency of the crystal, strain can be measured using Raman measurements. The strain can be estimated correctly because the GaAs LO peak and one of the phonon peaks of InGaAs may overlap. Since both materials have almost the same lattice constant, InAlAs has been used as a barrier layer instead of InGaAs in this study.

The penetration depth of the laser $(514.5 \mathrm{~nm})$ at this wavelength is about $100 \mathrm{~nm} .{ }^{10}$ The measured depth was 5 well layers from the top well layer, as the barrier layers are transparent at the $\mathrm{Ar}^{+}$excitation source wavelength. Each well layer is $20 \mathrm{~nm}$ in thickness. It is possible that the Raman spectrum included the effects of the lower wells. However, the intensity of the laser light decreased exponentially with depth from the top well and Raman light decreased exponentially from the inside to the top. The Raman spectrum origi-

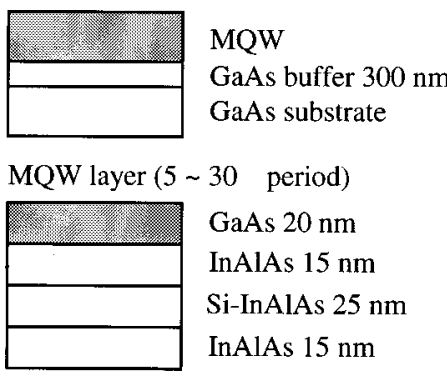

FIG. 1. Schematic drawing of the sample structures (In content was 5\%, $10 \%$, or $15 \%)$ 


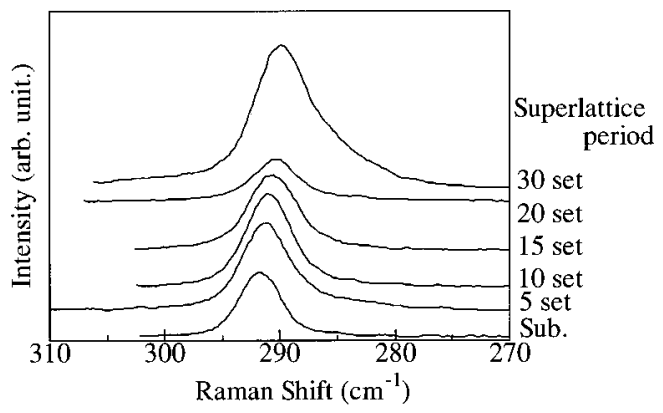

FIG. 2. Raman spectra for GaAs well layer at room temperature (RT) with various superlattice periods. Indium content was $15 \%$.

nated mainly from the first well. We can observe that the strain is released within 5 well layers from the surface, however the strain from the individual well layers cannot be separated.

Direct observation of the SLs was carried out using a transmission electron microscope (TEM), JFM-2010 (JEOL Ltd.). As for observing the cross section, the influence of strain to the SL was characterized. The acceleration voltage was $200 \mathrm{kV}$ and the space resolution was $0.19 \mathrm{~nm}$.

\section{RESULTS AND DISCUSSION}

Figures 2-4 show the Raman spectra of the GaAs well layers with In contents of 15\%, 10\%, and 5\% in the SL with varying periods. A peak around $290 \mathrm{~cm}^{-1}$ was due to the $\mathrm{LO}$ phonon in GaAs. The extra shift in the GaAs LO phonon was due to stress in the GaAs layers. The frequency of the GaAs LO phonon shifted to a lower wave number with an increase in period, as shown in Figs. 2 and 3, for In contents of 15\% and $10 \%$, respectively. However the GaAs LO phonon frequency changed in a complicated manner for an In content of 5\%, as shown in Fig. 4. These results are explained as follows. At first, the extra peak shift of the GaAs LO phonon and strain in the GaAs well layers were plotted. The stress $\sigma$ in the GaAs layer was calculated based on the amount of extra shift of the LO phonon frequency, using the following equation: ${ }^{11,12}$

$$
\sigma=\frac{\left(2 \pi c \times \tilde{v}_{0}\right)\left(2 \pi c \times \Delta \tilde{v}_{\mathrm{LO}}\right)}{p s_{12}+q\left(s_{11}+s_{12}\right)} 10^{9} \mathrm{dyn} / \mathrm{cm}^{2},
$$

where $c$ is the velocity of light, $p$ and $q$ are transformation potentials, $s_{11}$ and $s_{12}$ are elastic compliance, ${ }^{13} v_{0}$ is the

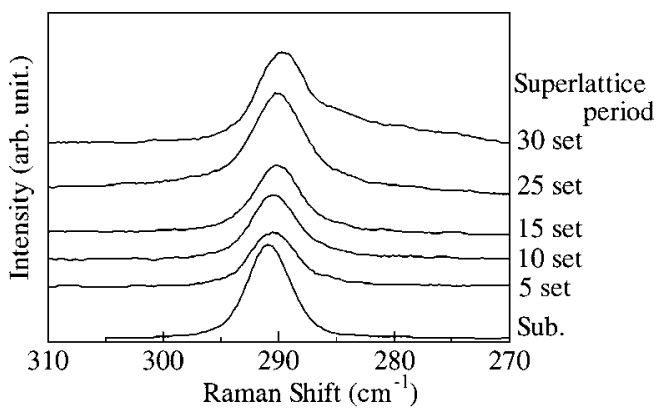

FIG. 3. Raman spectra for GaAs well layer at RT with various superlattice periods. Indium content was $10 \%$.

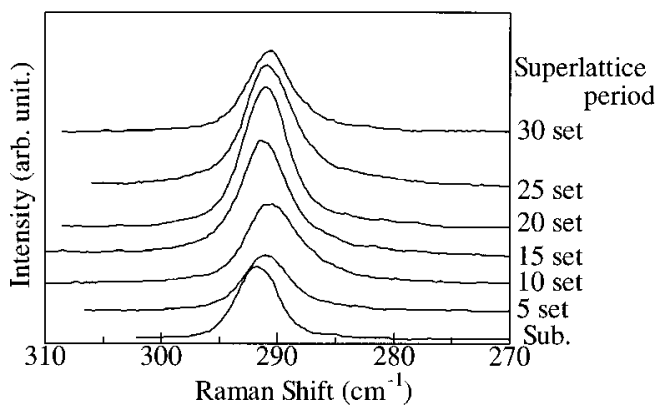

FIG. 4. Raman spectra for GaAs well layer at RT with various superlattice periods. Indium content was $5 \%$.

frequency of the intrinsic GaAs LO phonon, and $\Delta \tilde{v}_{\mathrm{LO}}$ is the amount of extra shift of the GaAs LO phonon. Strain $\eta$ is given by the following equation:

$$
\eta=2 s_{12} \sigma \times 10^{-12} \% \text {. }
$$

Figure 5 shows the relations between period and strain in the GaAs layers of the $(\mathrm{GaAs})_{n}(\mathrm{InAlAs})_{n}$ superlattice. It is clear from the figure that the strain in the $(\mathrm{GaAs})_{n}(\mathrm{InAlAs})_{n}$ superlattice with In contents of $15 \%$ and $10 \%$, respectively, increased with period. However, strain in the $(\mathrm{GaAs})_{n}(\mathrm{InAlAs})_{n}$ with an In content of $5 \%$ increased with the period until it reached 10 and then decreased suddenly when the period was 10. The strain increased again when the period was greater than 15 . In the case of a $(\mathrm{GaAs})_{n}(\mathrm{InAlAs})_{n}$ superlattice with an In content of $15 \%$ and $10 \%$, the lattice mismatches between the GaAs well layer and the InAlAs barrier layer were $0.82 \%$ and $1.17 \%$, respectively. The difference in the lattice constants between the well and the barrier layers was large, hence some of the strain was released with the formation of defects even when the period was small. However, as for a $(\mathrm{GaAs})_{n}(\mathrm{InAlAs})_{n}$ superlattice with an In content of 5\%, the lattice mismatch between the GaAs well and the InAlAs barrier layers was $0.47 \%$, so the difference in lattice constants was small, and strains accumulated without the introduction of significant defects when the period was less than 10 . When the period

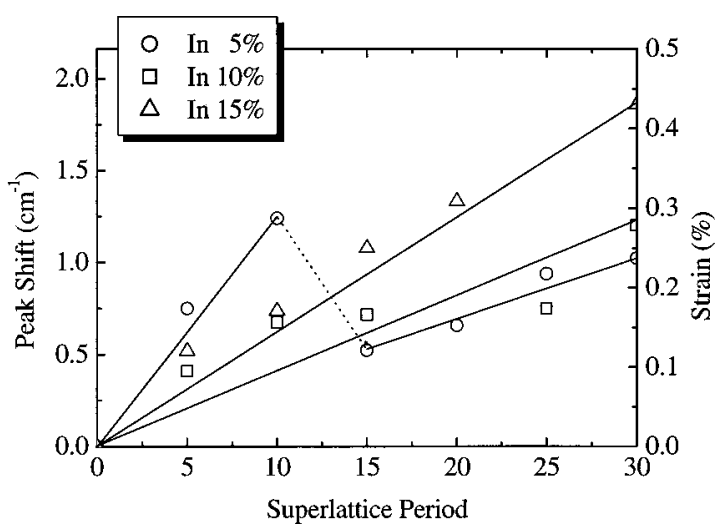

FIG. 5. Dependence of superlattice period on Raman peak shift. Strain in a GaAs well layer was calculated based on the peak shift. 


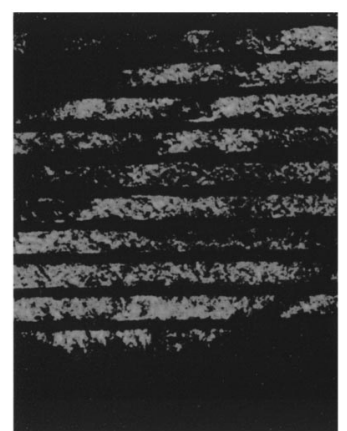

(a)

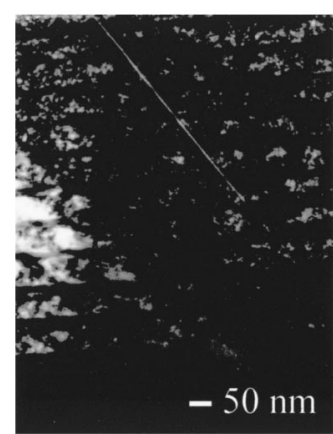

(b)
FIG. 6. TEM microphotograph of InAlAs/GaAs quantum well structure. The periods of superlattice (a) and (b) were 10 and 15 , respectively. In content was fixed at $5 \%$.

exceeds 10, however, large defects were introduced suddenly and the strain was released.

$(\mathrm{GaAs})_{n}(\mathrm{InAlAs})_{n}$ superlattice structures with an In content of 5\% were observed using a TEM. Figure 6 shows a part of the cross-sectional view of the superlattice. The periods of the superlattice shown in Figs. 6(a) and 6(b) are 10 and 15, respectively. A clear crack is seen in Fig. 6(b) when the number of periods was 15 , while no such crack was observed when the period was 10 . The results are consistent with those described above. Only one large crack, spread perpendicularly over all layers, was observed in the superlattice. This means that the crack density was low, judging by the TEM image. It is possible that such a crack could accrue for a superlattice with an In content of $10 \%$ or $15 \%$ when the period was larger than 30 . However, no crack was observed for those superlattices with a period less than 30 , as shown in Fig. 5, which suggests that the sudden decrease of strain does not occur in those superlattices.

\section{SUMMARY}

We have reported in this article the effect of the number of periods in a superlattice on the accumulation and release of strain. In the case of a superlattice, the difference in lattice constants between the well and the barrier layers is small, and larger stress is accumulated when the number of periods is small. However, significant defects are introduced suddenly when the period reaches a threshold value, and stress is released. Stress accumulates again with an increase in the number of periods after a sudden release.

\section{ACKNOWLEDGMENTS}

This study was performed with the support of Special Coordination Funds of the Science and Technology Agency of the Japanese Government.

${ }^{1}$ L. Esaki and R. Tsu, IBM J. Res. Dev. 14, 61 (1970).

${ }^{2}$ N. Miura, K. Joshin, S. Hiyamizu, and M. Abe, Jpn. J. Appl. Phys., Part 2 20, L598 (1981)

${ }^{3}$ S. L. Su, R. Fischer, W. G. Lyons, O. Tejayadi, D. Arnold, J. Klem, and H. Morkoç, J. Appl. Phys. 54, 6725 (1983).

${ }^{4}$ T. Mori, H. Ohnishi, K. Imamura, S. Muto, and N. Yokoyama, Appl. Phys. Lett. 49, 1779 (1986).

${ }^{5}$ A. Ketterson, M. Moloney, W. T. Masselink, C. K. Peng, R. Fischer, W. Kopp, and H. Morkoç, IEEE Electron Device Lett. EDL-6, 682 (1985).

${ }^{6}$ T. Inata, S. Muto, S. Sasa, T. Fujii, and S. Hiyarnizu, Extended Abstracts of 19th Conference on Solid State Devices and Materials, Tokyo, Japan, 1987, p. 359

${ }^{7}$ J. A. Moriarty and S. Krishnamurthy, J. Appl. Phys. 54, 1892 (1983).

${ }^{8}$ J. W. Matthews and A. E. Blakesee, J. Vac. Sci. Technol. 14, 989 (1977).

${ }^{9}$ R. People and J. C. Bean, Appl. Phys. Lett. 47, 322 (1995).

${ }^{10}$ Handbook of Chemistry and Physics, 76th ed., edited by D. R. Lide (Chemical Rubber Corp., Boca Raton, FL, 1995).

${ }^{11}$ E. Anastassakis, A. Pinczuk, and E. Butrstein, Solid State Commun. 8, 133 (1970).

${ }^{12}$ F. Cerderira, C. J. Buchenauer, F. H. Pollak, and M. Cadona, Phys. Rev. B 5, 580 (1972).

${ }^{13}$ E. Anastassakis, A. Pinczuk, and E. Burstein, Solid State Commun. 8, 133 (1970) 